Proc. Indian Acad. Sci. (Chem. Sci.), Vol. 89, Number 2, April 1980, pp. 119-123.

(C) Printed in India.

\title{
Thermal behaviour of resorcinol-1,2-dichloroethane resin
}

\author{
JITU PATEL, RAJNI PATEL and K C PATEL \\ Department of Chemistry, Sardar Patel University, Vallabh Vidyanagar 388 120, India \\ MS received 3 December 1979; revised 21 January 1980

\begin{abstract}
Resorcinol-1,2-dichloroethane resin was prepared by Friedel-Craft polymerization from resorcinol and 1,2-dichloroethane. The resin sample was characterised by IR and UV spectra and the average molecular weight was determined by vapour pressure osmometry. Kinetic parameters from TG and DTA thermograms are reported.
\end{abstract}

Keywords. Resorcinol ; dichloroethane resin; differential thermal analysis.

\section{Introduction}

Friedel-Craft's reaction of benzene or substituted benzene and 1,2-dichloroethane gives resins in which benzene nuclei are linked through ethylene bridges (Shinkle 1935; Towne 1937; Sisido and Kato 1940; Shishido and Nita 1945; Shishido and Miyoshi 1945; Shishido and Irie 1945). Anisolic and derivatives of anisolic resins with methylene bridges have been reported by Shah (1973). A literature survey revealed that resin having resorcinol with ethylene bridges has not been reported. This paper reports the synthesis and thermal behaviour of resorcinol-1, 2-dichloroethane resin.

\section{Experimental}

\subsection{Friedel-Craft polymerisation}

The chemicals used were of analytical grade. The reaction was carried out in a three-necked flask. The preliminary experimental conditions of varying the monomer concentration, catalyst concentration, reaction period and temperature showed that the optimum condition for the preparation of the resin is as follows. Resorcinol $(0 \cdot 10 \mathrm{~mol}), 1,2$-dichloroethane (DCE) $(0.25 \mathrm{~mol})$ and aluminium chloride $(0.20 \mathrm{~mol})$ as catalyst were mixed and heated at $115^{\circ} \mathrm{C}$ for $2.5 \mathrm{hr}$. The reaction mixture was poured in ice and hydrochloric acid followed by repeated washing with distilled water. The resin obtained was further purified using methyl ethyl ketone as solvent and petroleum ether $\left(40^{\circ}-60^{\circ} \mathrm{C}\right)$ as nonsolvent. 


\subsection{Characterisation}

The IR-absorption spectra of resorcinol-1,2-dichloroethane (resorcinol-1,2-DCE) resin were scanned on a Carl Zeiss model UR-10. DK-2A Beckman quartz spectrophotometer was used for light absorption measurements in the ultraviolet regions. The number of averago molecular weight $(\mathbf{M} \bar{n})$ of the resin sample was determined using a Hewlett-Packard Model-302B vapour pressure osmometer. The differential thermal analysis (TGA) and the thermogravimetry (TG) equipment were used to study the thermal property. The kinetic parameters were evaluated from TG-study (Chatterjee 1965; Anderson and Freeman 1961; Broido 1969; Flynn and Wall 1966). The data obtained are given in table 1. Table 2 shows the kinetic parameters obtained from DTA using Reich (1969) and Kissinger (1956) methods.

\section{Results and discussion}

Resorcinol-1,2-DCE resin was amorphous in nature and did not soften upto $280^{\circ} \mathrm{C}$.

The $\mathbf{M} \bar{n}$ of resin was 827 . The resin was soluble in diethylether, acetone and methyl ethyl ketone. The IR spectra of resin showed a band in the region from $2800-2975 \mathrm{~cm}^{-1}$ ascribed to aromatic $\mathrm{C}-\mathrm{H}$ stretching and methylene group. The bands were obtained in the range of 1220 to $1250 \mathrm{~cm}^{-1}$ and 1350 to $1390 \mathrm{~cm}^{-1}$ due to aromatic hydroxyl group. A band at $282 \mathrm{~nm}$ in the UV-spectra of this resin sample indicated that the growth of polymeric chain through ethylene bridge did not significantly alter the resonance system of the individual phenolic unit.

DTA and TG analyses of the resorcinol-1,2-DCE have been carried out at $1^{\circ}$, $2 \cdot 5^{\circ}, 4 \cdot 0^{\circ}$ and $6 \cdot 5^{\circ} \mathrm{C} \mathrm{min}^{-1}$ in static air. The $\mathrm{TG}$-thermogram of the resin sample showed a single-step degradation corresponding to $100 \%$ weight loss. The temperature ranges for the decomposition at the different $\mathrm{RH}$ respectively were: (a) $290^{\circ}$ to $500^{\circ}$, (b) $255^{\circ}$ to $465^{\circ}$, (c) $295^{\circ}$ to $515^{\circ}$ and (d) $280^{\circ}$ to $585^{\circ} \mathrm{C}$.

The DTA thermograms were exothermic in nature, and all peaks were associated with humps (h). The decomposition reaction as revealed from TG is assumed to take place at the hump temperature for all the heating rates. The temperature for the humps and the peak maxima at different $\mathrm{RH}$ respectively are: (a) $275^{\circ}$, $390^{\circ}$, (b) $290^{\circ}, 405^{\circ}$, (c) $290^{\circ}, 415^{\circ}$ and (d) $300^{\circ}, 440^{\circ} \mathrm{C}$.

The activation energies $\left(E_{\mathrm{A}}\right)$ obtained from the TG-thermograms using the method of Chatterjee (1965) for 25 and $50 \mathrm{mg}$ of the sample heated at various heating rates were fairly constant, i.e., $\sim 20 \mathrm{kcal} \mathrm{mol}^{-1}$ and the decomposition of the resin followed nearly first order kinetics (table 1 ).

The Anderson-Freeman method yielded activation energies for the decomposition of resorcinol-1,2-DCE resin, viz., (a) $\sim 16$, (b) $\sim 16$, (c) $\sim 15$ and (d) $\sim 14$ $\mathrm{kcal} \mathrm{mol}^{-1}$ following the first order kinetics for all the RH and for 25 and $50 \mathrm{mg}$ sample, respectively.

The activation energies from Broido method for 25 and $50 \mathrm{mg}$ of the resin sample were (a) $\sim 16$, (b) $\sim 16$, (c) $\sim 14$ and (d) $\sim 13 \mathrm{kcal} \mathrm{mol}^{-1}$ respectively at the RH mentioned above having a reaction order of 1.00 .

The activation energy from Flynn-Wall method for 25 and $50 \mathrm{mg}$ of the resin sample was 29.0 and $28.0 \mathrm{kcal} \mathrm{mol}{ }^{-1}$, considered to bo fairly constant. 


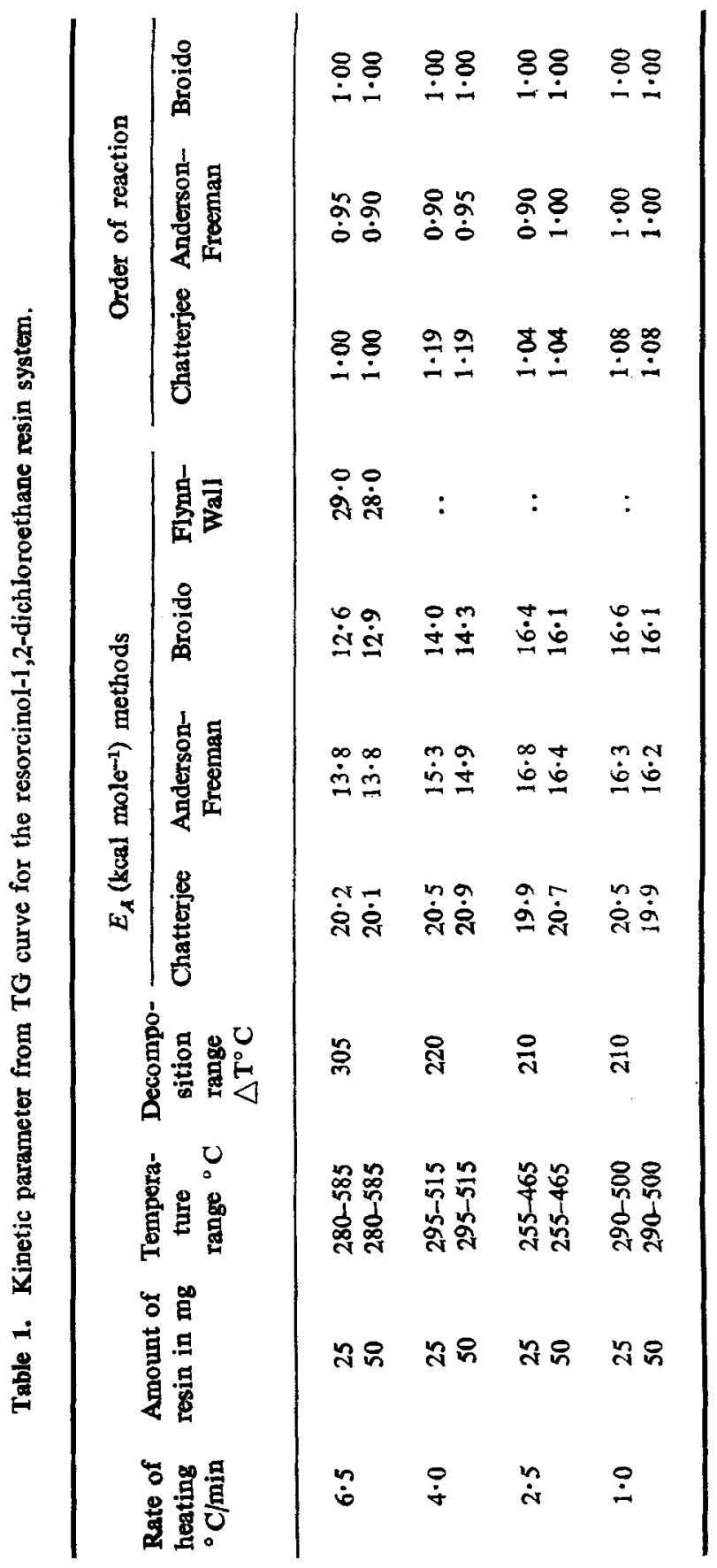


Table 2. Kinetic parameter from DTA curve for the resorcinol-1,2-dichloroethane resin system.

\begin{tabular}{|c|c|c|c|c|c|}
\hline \multirow{2}{*}{$\begin{array}{l}\text { Rate of } \\
\text { heating } \\
{ }^{\circ} \mathrm{C} \text { min }^{-1}\end{array}$} & \multirow{2}{*}{$\begin{array}{c}\text { Peak } \\
\text { temperature } \\
{ }^{\circ} \mathrm{C}\end{array}$} & \multicolumn{2}{|c|}{$E_{A}$ kcal. mole ${ }^{-1}$} & \multicolumn{2}{|c|}{ Order of reaction $n^{\prime}$} \\
\hline & & $\begin{array}{l}\text { Reich } \\
\text { method }\end{array}$ & $\begin{array}{l}\text { Kissinger } \\
\text { method }\end{array}$ & Reich & Kissinger \\
\hline $6 \cdot 5$ & $\begin{array}{l}300(h) \\
440\end{array}$ & $53 \cdot 4$ & $32 \cdot 0$ & 0.92 & 0.80 \\
\hline $4 \cdot 0$ & $\begin{array}{l}290(\mathrm{~h}) \\
415\end{array}$ & $53 \cdot 1$ & .. & 0.72 & . \\
\hline $2 \cdot 5$ & $\begin{array}{l}290(\mathrm{~h}) \\
405\end{array}$ & $54 \cdot 2$ & .. & 0.75 & .. \\
\hline $1 \cdot 0$ & $\begin{array}{l}275(h) \\
390\end{array}$ & $55 \cdot 3$ & .. & $0 \cdot 77$ & .. \\
\hline
\end{tabular}

The $E_{A}$ values given in table 1 and evaluated by various methods show considerable variation among one another. But those calculated by the Chatterjee method are nearly constant at all the RH involved in the study. Further it is noted that $E_{A}$ evaluated using the Anderson-Freeman and the Broido method showed decreasing trend with increasing RH. This may be ascribed to the utilisation of the heat energy required for the molecular rearrangements depending on the relaxation time $\tau$. At high heating rate, the rearrangement of molecules is less likely and the heat is directly utilised for the breaking of bonds and there is a decrease in the heat capacity of the sample.

The $E_{A}$ values evaluated from the DTA-thermogram using the Reich and the Kissinger method given in table 2 show that they have a decreasing trend with increasing RH. Once again this behaviour agrees with that mentioned above. The molecular rearrangement assumed to take place at low heating rate may indicate the flexible nature of the molecules.

The activation energy evaluated using the Kissinger method is $\sim 32 \mathrm{kcal} \mathrm{mol}^{-1}$. The Reich method deals with the activation energy for a single thermogram obtained at a single heating rate, whereas the Kissinger method involves many thermograms at different heating rates by keeping other experimental conditions constant. Maintaining the experimental conditions except $\mathrm{R} H$ are difficult and so the results are subject to reasonable variations.

\section{Acknowledgements}

One of the authors (JP) is grateful to the University Grants Commission, New Delhi, for a fellowship.

\section{References}

Anderson D A and Freeman E S 1961 J. Polym. Sci. 54253

Broido A 1969 J. Polym. Sci. A2 1761

Chatterjee P K 1965 J. Polym Sci. A3 4253

Flynn J H and Wall L A 1966 J. Polym. Sci. B4 323 
Kissinger H E 1956 J. Res. Nat. Bur. Stand. 57217

Reich L 1969 Die Makromol. Chem. 12342

Shah K G and Mankad B N 1973 Die Angew: Makromolecular Chem. 321

Shah K G, Desai D H and Mankad B N 1973 Die Angew. Makromolecular Chem. 33177

Sisido K and Kato S 1940 J. Soc. Chem. Ind. Jpn. 43232

Shinkle S D 1935 Chem. Abst. $298175^{8}$

Shishido K and Nita T 1945 J. Soc. Chem. Ind. Jpn. 4833

Shishido K and Irie I $1945 \mathrm{~J}$. Soc. Chem. Ind. Jpn. 4810

Shishido K and Miyoshi I 1945 J. Soc. Chem. Ind. Jpn. 4837

Towne C C 1937 Chem. Abst. $315900^{3}$ 